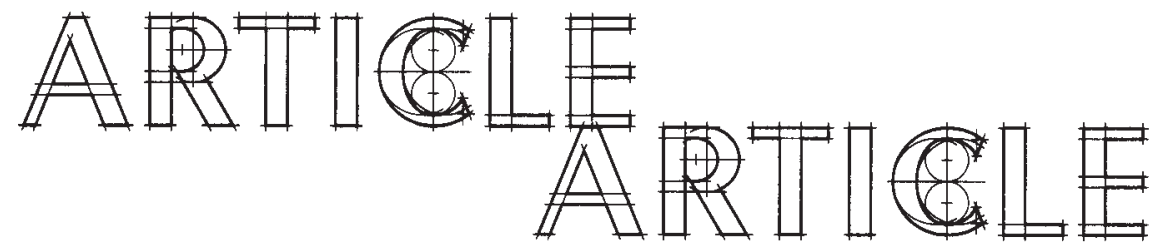

\title{
Keratoconus: Clinical Associations and Treatment Options
}

\section{Caractéristiques et traitements du kératocône}

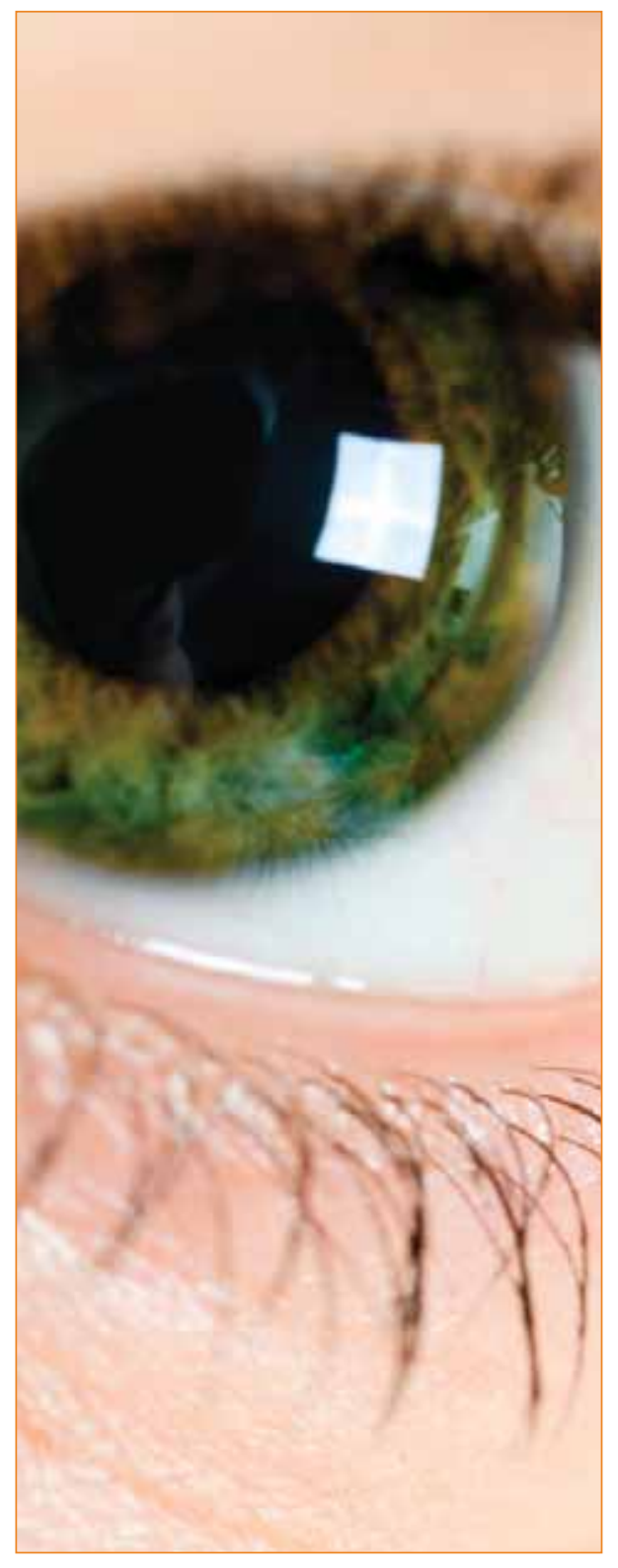

Abstract: The focus of the present review of literature is keratoconus, a progressive thinning of the cornea. $\mathrm{Be}$ cause k eratoconus usually induces irregular astigmatism, the most affected patients ex perience a decreased visual acuity that limits the correction using ophthalmic lenses. The CLE K (Collaborative L ongitudinal E valuation of Keratoconus) is a study carried out in several centers with the aim of describing the evolution and associations between the visual and physiological manifestations of keratoconus. Since the treatment of keratoconus varies acoording to its severity, this paper proposes a summary of the results of the CLE K and a review of the therapeutic options.

Sommaire: L a présente revue de littérature traite du kératoône, un amincissement progressif de la cornée. L e kératoône induit habituellement de l'astigmatisme irrégulier de sorte que les patients les plus affectés ont une acuité visuelle diminuéé limitant ainsi la correction à tive $\mathrm{L}$ ongitudinal $\mathrm{E}$ valuation of Keratoconus) est une étude effectuée dans plusieurs centres dans le but de dé crire l'évolution et les associations entre les manifestations visuelles et physiologiques des kératocônes. É tant donné que le traitement du k ératocône varie selon la sévé rité, le présent article propose un sommaire des résultats du CL E K et un survol des options thérapeutiques.

\section{INTRODUCTION}

Keratoconus is the most common dystrophy inducing corneal ectasia. According to the $\mathrm{Na}$ tional Keratoconus Institute, the occurrence of this disease is one in 2,000. Keratoconus is charl'aide de lentilles ophtalmiques. L a CL E K (Collabora-
This article first appeared in French in the July 2008 issue of the CJO (Vol. 70

No. 4). Clinical articles are published in the language submitted by the author(s), unless there is a clear indication of interest from readers and permission of the clinical editors and author(s). We are pleased to present a translated version of the original article.

Authors:

Patrick Simard

OD, MSC

École d'optométrie,

Université de Montréal, QC and

Clinique d'Optométrie

Bélanger, Montreal, QC

Claude J. Giasson

$\mathrm{OD}, \mathrm{PhD}, \mathrm{FAAO}$

École d'optométrie,

Université de Montréal, QC and

Laboratoire

d'Organogénèse

Expérimentale (LOEX),

Saint-Sacrement Hospital,

Québec, QC

Key words: Keratoconus, CLEK, Contact Lenses, Penetrating Keratoplasty, Intra-corneal Ring, LASIK, PRK, Riboflavin

Mots clés: Kératocône, CLEK, Lentilles Cornéennes, Kératoplastie Pénétrante, Anneaux intra-cornéens, LASIK, KPR, Riboflavine 
acterized by a progressive thinning of the corneal stroma and corneal ectasia over several decades. This disease generally starts in a very productive period of patients' lives: the twenties. This usually bilateral non-inflammatory process induces myopia and irregular astigmatism that limits correction with ophthalmic lenses. The treatment for keratoconus varies according to severity of the case. The CLEK (Collaborative Longitudinal Evaluation of Keratoconus) study was done in several centers over an eight-year period with the aim of describing the evolution and associations between the visual symptoms and physiological signs of keratoconus. Over a thousand patients were recruited in 15 different U.S. clinics. This article represents part of the literature review done as part of a master's degree on the density of keratocytes in contact lens wearers with or without keratoconus. A summary of the CLEK results followed by an overview of the therapeutic options available to patients with keratoconus unsatisfied with their condition will be presented.

\section{Collaborative Longitudinal Evaluation of Keratoconus (CLEK)}

The overall goals of the CLEK involved characterizing the visual and corneal changes as well as the quality of life of patients with keratoconus. The study also intended to describe the progression of changes over time. To do so, patients were first examined when recruited (1995-2006), then every year afterwards. During each patient's visit, the CLEK clinicians evaluated the following aspects: vision-related quality of life, case history, time wearing contact lenses, visual acuity, corneal signs, corneal scarring, topography, treatment method, and the parameters of their adjustment to gas-permeable lenses allowing apical clearance. Finally, the cornea and the lens/cornea relationship through fluorescein were photographed. This accumulation of data on case development was covered in several different publications that are summarized in the following section.

\section{Vision-related factors}

The National Eye Institute visual function questionnaire (NEI-VFQ) was filled out at the annual followup exam by 1,166 patients. This questionnaire contains 51 different scales. A binocular visual acuity lower than
$6 / 12$ is associated with a low quality of life on all scales except those about general health and eye pain. Keratometric measurements higher than 52 diopters (D.) are correlated with poor results on the scales pertaining to mental health (loss of control and concern caused by vision), work (difficulty in close-up vision tasks at work), automobile driving (difficulty driving during the day and at night), dependency (need for others and necessity of staying at home) and eye pain (pain and discomfort around the eyes). ${ }^{1,2}$ According to another study, there is no association between the subjective reduction in comfort when wearing gas-permeable lenses and the increase in the severity of keratoconus measured by the steepest keratometric curve or by the first contact lens allowing apical clearance. ${ }^{3}$

In a multi-centre study of this scope, it was important to ensure repeatability of the observations and consistency among the various centers. Moreover, in a sample frequently wearing contact lenses, like the patients with keratoconus, the feasibility of assessing the contact lens adjustment based on apical clearance using a photograph and direct observation by the clinician was possible and useful., ${ }^{4,5}$ The lens/cornea relationship at the corneal apex of the gas-permeable contact lenses observed in the presence of fluorescein was assessed and categorized into four qualitative divisions: significant touch, touch, clearance and significant clearance. The repeatability and validity between the evaluations of this type done by the clinicians during visits and by the clinicians using photographs are excellent. ${ }^{6}$ The repeatability of the visual acuity measurements of keratoconus is comparable to normal subjects. ${ }^{7}$ On the other hand, the repeatability of refractions of subjects with keratoconus is lower than normal subjects. Over-refraction with contact lenses in place increases repeatability, but it remains lower than over-refraction done with normal subjects. ${ }^{8}$ Only $36 \%$ of subjective refractions of subjects with keratoconus yielded repeatable spherical measurements at $+/-0.50$ diopters (D.) compared to $90 \%$ for normal subjects. ${ }^{9}$ It is important to account for this clinical variation in refraction when choosing the correction to apply to keratoconic patients.

On the other hand, the repeatability of the three topography instruments used in axial and tangential mode in this study, the EyeSys Model II, the Dicon CT 200 


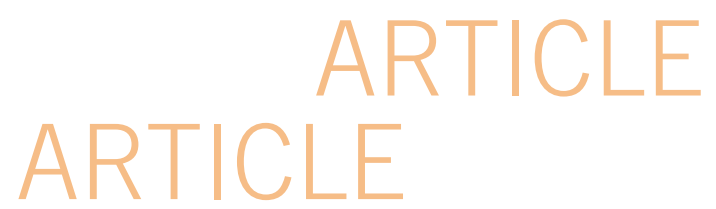

and the Keratron Corneal Analyser, is also reduced in the presence of a keratoconic irregular cornea. ${ }^{10}$ The repeatability of the topographies of keratoconic corneas using the Tomey 1 (TMS-1) instrument is also lower than that of normal subjects. ${ }^{11}$

\section{General characteristics of the CLEK study subjects}

The longitudinal observation of 1,209 patients helped describe the frequency of characteristics of these patients. The average age at recruitment was $39.3+/-10.9$ years of age with moderate to severe keratoconus. Ninety-five percent of the patients had a keratometry of at least 45 diopters (D.). Sixty-five percent were bilateral wearers of gas-permeable lenses and $73 \%$ of all wearers found them comfortable despite apical touch in $88 \%$ of adjustments. The best corrected visual acuity in each eye was $6 / 12$ or better in $78 \%$ of cases. Fifty-three percent had corneal scarring in at least one eye. Corneal opacification is associated with corneal staining, number of years worn, the presence of a Fleischer ring and steeper corneas. ${ }^{12}$ In the case history, $13.5 \%$ reported the presence of keratoconus in their family and 53\% a personal history of atopy. ${ }^{13}$ The only difference between the men and women following statistical analysis was in the presence of Vogt striae and monocular and binocular highcontrast visual acuity. The women had fewer Vogt striae and had lower visual acuity. In general, women tend to report symptoms more easily. ${ }^{14}$ A reduction in high- or low-contrast visual acuity was seen in the presence of corneal scarring. ${ }^{12,15}$

\section{Factors associated with the presence of cor- neal scarring}

The evaluation of the presence of corneal scarring by the clinicians matches the evaluation done by external observers using photographs. Taking photos helped ensure that all of the study's clinicians had the same evaluation criteria. ${ }^{16}$ The risk of having corneal scarring is positively associated with the following factors: degree of corneal curvature, age, the presence of corneal staining or a Fleischer ring, wearing lenses. ${ }^{17}$ In the latter case, contact lens wearers have twice the risk of developing corneal scars. It is important to eliminate apical touch of contact lenses to reduce the risk of developing scars. ${ }^{18}$ Figures 1 and 2 show the topography and biomicroscopic aspect of a cornea from a keratoconic patient with scarring.

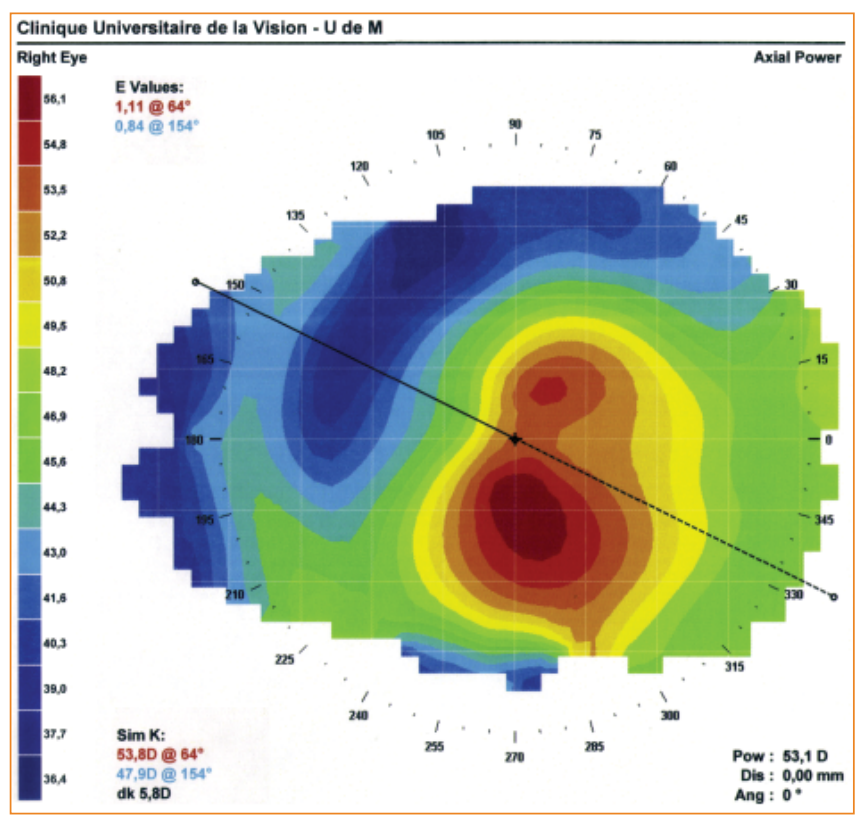

Figure 1. Medmont topography of a steeped cornea with keratoconus

The increase in the corneal curve is related to the presence of Vogt striae, the Fleischer ring and corneal scarring. These biomicroscopically visible signs are more common, namely about $60 \%$ of eyes, in corneas with keratoconus that is considered severe. ${ }^{19}$ The asymmetry between the two eyes of keratoconic patients in terms of corneal curvature, visual acuity, ametropia and corneal scarring is statistically significant when compared to that of myopic subjects who wear contact lenses. There is also an association between unilateral eye rubbing and asymmetry; the rubbed eye being the eye with the greatest curvature. ${ }^{20}$ Patients with a more severe form of keratoconus are also more asymmetric in this disease. ${ }^{21}$

Several studies have long observed in the corneal stroma the presence of proteinases, enzymes that can denature the proteins making up the cornea. For marking one of these types of enzymes, esterases, the CLEK study adapted a technique of transferring conjunctival cells onto a membrane using impression cytology. This technique is preferable to taking a biopsy over the entire conjunctival thickness. The specimens from keratoconic subjects had higher levels of esterases than those in 


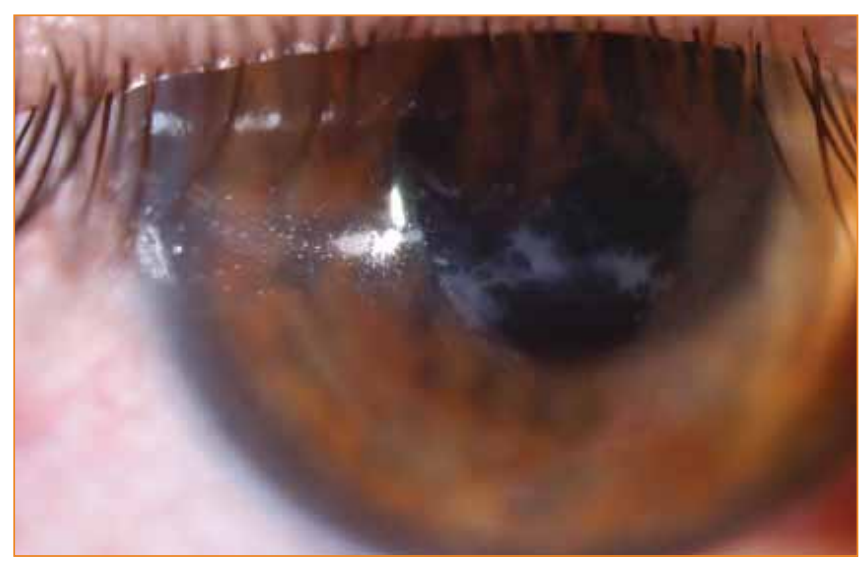

Figure 2. Corneal scarring in the same patient as Figure 1

the control group, suggesting the presence of enzymes capable of destroying the corneal tissue. ${ }^{22}$

On the other hand, contrary to previous publications indicating the possibility that keratoconus is caused by collagen anomalies, keratoconus is not associated with an increased risk of having a connective tissue disease. ${ }^{13}$ Moreover, the CLEK study did not investigate the pathophysiology of keratoconus. Increased knowledge of the mechanisms inducing keratoconus is needed to better define appropriate treatments based on severity.

\section{Treatment}

The first therapeutic approach involves adjusting rigid contact lenses in order to correct the irregular surface of the cornea and improve vision, when the patient's visual acuity is no longer satisfactory using glasses. There are several types of gas-permeable lenses specialized for adjusting keratoconic corneas. Describing these lenses is outside the scope of this article. However, one new development in the field deserves to be mentioned. It is now possible to manufacture customized soft contact lenses. The lenses take into account aberrations of the eye and corneal topography to achieve optimal correction. $^{23}$

If the patient becomes intolerant to gas-permeable lenses or if declining visual acuity is no longer sufficient for meeting the patient's visual needs, "piggyback" lenses are sometimes prescribed. This wearing method combines a soft carrier lens, applied directly onto the cornea, with a small gas-permeable lens that can move around on the soft lens. This latter lens is sometimes manufactured so as to facilitate centering of the semi-

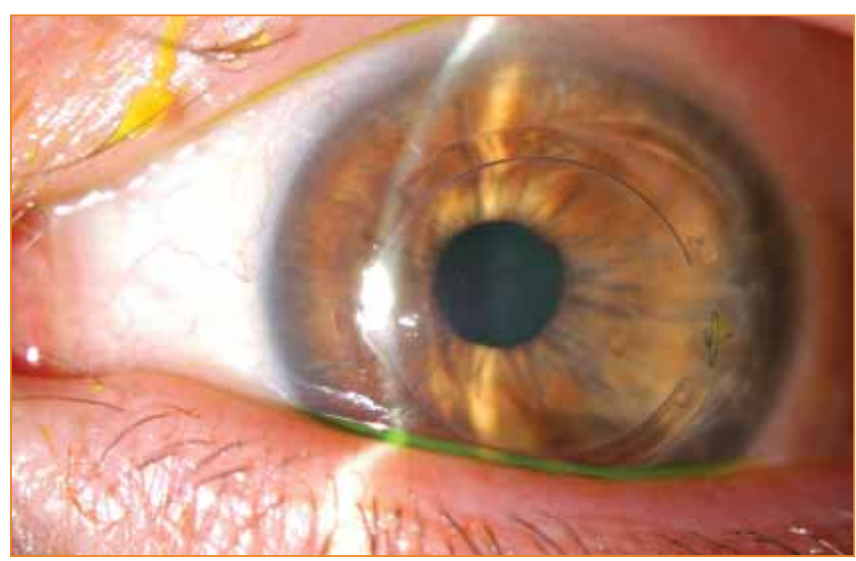

Figure 3. Keratoconic cornea with Intacs intra-corneal rings

rigid lens. As such, the set combines the comfort of soft lenses with the visual acuity brought about by gas-permeable lenses.

Most often after failure of contact lenses, penetrating keratoplasty (PK) called full-thickness corneal transplant is done. This procedure involves substituting the central portion of the cornea of a keratoconus patient with a healthy cornea from a deceased donor. The frequency of keratoconus and the waiting time varies depending on the countries concerned. In Canada, a retrospective study over 10 years shows that keratoconus is the second indication for penetrating keratoplasty with $10 \%$ of cases following pseudophakic bullous keratopathy.24 The waiting time in Quebec is at least two years. In Brazil, keratoconus comes after ulcers and pseudophakic bullous keratopathy. ${ }^{25}$ In China, keratoconus is the fourth indication for $\mathrm{PK}^{26}$ just like in the United States. ${ }^{27}$ The average time elapsed between keratoconus diagnosis and the transplant is 8.5 years in England. ${ }^{28}$ According to a study done in a London tertiary reference centre, $21.6 \%$ of keratoconic patients will need a corneal transplant. ${ }^{29}$ The best visual acuity lower than $6 / 12$, astigmatism greater than 10 D., a corneal curvature greater than 55 D., an age of 30 years or less and a diagnosis 5 years ago or less increase the chance of needing a corneal transplant. ${ }^{30}$ However, the significant cost connected with penetrating keratoplasty and the aberrations caused by the resulting irregular astigmatism is motivating surgeons to consider this approach as a last resort. Other techniques are now developed to prevent or delay penetrating transplant.

One of those techniques, more delicate to perform 
but less likely to result in significant astigmatism, involving replacing only part of the cornea, is lamellar keratoplasty. Microkeratome-assisted deep lamellar keratoplasty involves creating a corneal lamella in the host cornea and introducing the donor stroma and then replacing the lamella. This technique enables keeping the host endothelium. Some suggest injecting an air bubble into the anterior chamber to minimize the risks of perforation before the formation of the lamella. ${ }^{31}$ In some studies, refractive surgery was done six months after the stromal transplant using an excimer laser to correct the patient's ametropia. The laser treatment is performed using the photorefractive keratoplasty (PRK) or LASIK (Laser in situ keratomileusis) method, in other words by removing the lamella to expose the stroma to the laser. The results seem promising, but follow-ups were only done over a period of 7 to 22 months. In a study on 9 eyes of 7 keratoconus subjects, corneal thickness went from 432.7 to $578 \mu \mathrm{m}$ on average after surgery. The corrected visual acuity of all patients improved by an average of five lines. ${ }^{32}$ Another study on 50 eyes of 50 patients measured a best-corrected visual acuity (BCVA) of $6 / 12$ in $88 \%$ of patients one year after this procedure. $^{33}$ PRK or LASIK was not done in this latter study. It should be noted that the use of refractive surgery techniques with incisions like LASIK is far from being unanimously approved among practitioners. In fact, these techniques are contra-indicated for patients with keratoconus, because they increase corneal instability. Other promising approaches discussed further on are currently being tested.

One experimental therapeutic approach involves colonizing a polymer with keratocytes to then hope to replace the cornea of patients affected by the new biocompatible material. ${ }^{34}$ This latter technique has been used successfully on four different patients whose corneas had completely opacified..$^{35}$

One last surgical option involves inserting rings into the mid-periphery of the corneal stroma of patients whose corneas are free of scarring. These half-moonshaped intra-corneal rings attempt to flatten the ocular surface. This reversible technique ${ }^{36}$ is especially applicable to patients with mild keratoconus who no longer tolerate contact lenses and have poor visual acuity with glasses. Based on topography, location and size of the cone, surgeons implant one or two segments horizontally in lower or higher position. ${ }^{37}$ The segments must be placed asymmetrically in relation to the centre of the cornea for best results. ${ }^{38}$ Implantation in more advanced cases required adjustment of a contact lens because the correction made by the intra-corneal rings was limited. ${ }^{39}$ Two types of rings are marketed: Intacs and Ferrara. Intra-corneal rings can correct between $-1.00 \mathrm{D}$ and $-3.00 \mathrm{D}$ and up to $1.00 \mathrm{D}$ astigmatism. The results from several studies that used them have recently been published. ${ }^{38,40-45}$ This procedure can also be performed on patients with marginal pellucid degeneration. ${ }^{46}$ Over a 12 -month period, the spherical equivalent of 36 eyes went from-7.29 D to $-4.80 \mathrm{D} .{ }^{47}$ Following insertion of segments in patients with keratoconus waiting for a corneal implant, best-corrected visual acuity went on average from $20 / 50$ to $20 / 32.37$ This limited procedure only mitigates the visual problems of keratoconic patients. Figure 3 shows a cornea with intra-corneal rings.

Some surgeons perform photorefractive keratectomies (PRKs) or therapeutic photo-keratectomies (TPKs) on keratoconus. Even though keratoconus is a contra-indication for incisive refractive surgery, a Russian team attempted to correct the myopia and astigmatism of subjects with keratoconus using an excimer laser treatment. ${ }^{48}$ Since keratoconus is an anomaly that starts in the anterior stroma and gradually progresses to the posterior stroma, the team claims to be able to halt the progression of the cone in mild keratoconus cases with PRK. This highly controversial treatment reportedly slows the progress in nearly $91 \%$ of cases over a follow-up period of 3.5 years. ${ }^{48,49}$ Another team from California performed the same procedure on keratoconus subjects with similar results. ${ }^{50,51}$ Long-term followup on these patients will better assess the relevance and actual effectiveness of this treatment, because the risk that treated keratoconus will progress further is present. While waiting, TPK can be used to remove apical opacity causing intolerance to contact lenses without correcting the ametropia. ${ }^{52}$

One new approach involves inserting an intra-ocular lens to correct myopia in subjects with stable keratoconus. The residual astigmatism is corrected by making a relaxing incision parallel to the limbus ${ }^{53}$ or keratoplasty with intra-corneal rings. ${ }^{54}$ Toric intra-ocular lenses can 
also be inserted into the anterior chamber. ${ }^{55}$ No largescale results are currently available for evaluating this technique.

With the aim of slowing the progress of keratoconus, it is possible to alter the cornea's resistance to deformations. The cornea's rigidity can be increased by modifying the interweaving of the collagen fibres. The method used involves incising the epithelium at the center of the cornea to apply drops of riboflavin (vitamin B2). The cornea is then exposed to ultraviolet A (UVA) radiation for a 30-minute period. This procedure was previously tested on rabbits to confirm its safety. ${ }^{56}$ UVA radiation is toxic for the endothelium of corneas that are thinner than $400 \mu \mathrm{m} .{ }^{57}$ Riboflavin alone is not toxic for the endothelium. ${ }^{58}$ However, apoptosis of keratocytes is observed on an anterior depth of $50 \mu \mathrm{m} .{ }^{59}$ The first study on humans involved 23 eyes of 22 different patients. The follow-up length varied between 3 months and 4 years. No treated keratoconus advanced. The keratometry dropped by $2.01 \mathrm{D}$ and ametropia by $1.14 \mathrm{D}$. in the case of 16 eyes. However, no improvement in visual acuity was observed. ${ }^{56}$ Further studies are needed to set the markers for this technique.

Some teams have successfully inserted, using a virus or plasmids, new genes into the corneal keratocytes of rabbits or rats in vivo. ${ }^{60-64}$ Other carriers have successfully been used in vitro in humans. ${ }^{65,66}$ For example, the effectiveness of the transduction of the gene implanted by cationic liposomes into human keratocytes is $40.5 \%{ }^{66}$ The hope for this treatment method lies in the possibility of identifying the defective genes to then modify them.

\section{Conclusion}

The CLEK is an excellent descriptive study of the changes in and characteristics of keratoconus. However, this study has several weaknesses. Since this study was started in 1995, the contact lenses do not use current designs. Moreover, the study does not look at posterior keratoconus, since the topography instruments used could not analyse the posterior curvature of the cornea. The characteristics described in this study help with better assessing the chance of progression and with guiding treatment. The many treatment options clearly show the heterogeneity of keratoconus. Keratoconus is the end result of several different processes affecting the cornea the same way that several processes affect the optic nerve in glaucoma. A better understanding of the pathophysiological mechanisms is needed for categorizing and defining the sub-groups affected by this disease in order to manage the development of it and select the best treatment option. At present, treatment selection is based on case severity without considering the process causing the disease.

\section{Bibliographie}

1. Vitale S. CLEK study reports on the quality of life. Am J Ophthalmol 2004;138:637-638.

2. Kymes SM, Walline JJ, Zadnik K, Gordon MO. Quality of life in keratoconus. Am J Ophthalmol 2004;138:527-535.

3. Edrington TB, Gundel RE, Libassi DP, et al. Variables affecting rigid contact lens comfort in the collaborative longitudinal evaluation of keratoconus (CLEK) study. Optom Vis Sci 2004;81:182-188.

4. Edrington TB, Barr JT, Zadnik K, et al. Standardized rigid contact lens fitting protocol for keratoconus. Optom Vis Sci 1996;73:369-375.

5. Gundel RE, Libassi DP, Zadnik K, et al. Feasibility of fitting contact lenses with apical clearance in keratoconus. Optom Vis Sci 1996;73:729-732.

6. Fink BA, Barr JT, Edrington TB, et al. A comparison of two methods of evaluating cornea-to-contact lens base curve fluorescein patterns in keratoconus. Optom Vis Sci 2001;78:589-598.

7. Gordon MO, Schechtman KB, Davis LJ, McMahon TT, Schornack J, Zadnik K. Visual acuity repeatability in keratoconus: impact on sample size. Collaborative Longitudinal Evaluation of Keratoconus (CLEK) Study Group. Optom Vis Sci 1998;75:249-257.

8. Raasch TW, Schechtman KB, Davis LJ, Zadnik K. Repeatability of subjective refraction in myopic and keratoconic subjects: results of vector analysis. Ophthalmic Physiol Opt 2001;21:376-383.

9. Davis LJ, Schechtman KB, Begley CG, Shin JA, Zadnik K. Repeatability of refraction and corrected visual acuity in keratoconus. The CLEK Study Group. Collaborative Longitudinal Evaluation of Keratoconus. Optom Vis Sci 1998;75:887-896.

10. McMahon TT, Anderson RJ, Joslin CE, Rosas GA. Precision of three topography instruments in keratoconus subjects. Optom Vis Sci 2001;78:599-604.

11. McMahon TT, Anderson RJ, Roberts C, et al. Repeatability of corneal topography measurement in keratoconus with the TMS-1. Optom Vis Sci 2005;82:405-415.

12. Szczotka LB, Barr JT, Zadnik K. A summary of the findings from the Collaborative Longitudinal Evaluation of Keratoconus (CLEK) Study. CLEK Study Group. Optometry 2001;72:574-584.

13. Zadnik K, Barr JT, Edrington TB, et al. Baseline findings in the Collaborative Longitudinal Evaluation of Keratoconus (CLEK) Study. Invest Ophthalmol Vis Sci 1998;39:2537-2546.

14. Fink BA, Wagner H, Steger-May K, et al. Differences in keratoconus as a function of gender. Am J Ophthalmol 2005;140:459-468.

15. Zadnik K, Barr JT, Edrington TB, et al. Corneal scarring and vision in keratoconus: a baseline report from the Collaborative Longitudinal Evaluation of Keratoconus (CLEK) Study. Cornea 2000;19:804-812.

16. Barr JT, Schechtman KB, Fink BA, et al. Corneal scarring in the Collaborative Longitudinal Evaluation of Keratoconus (CLEK) Study: baseline prevalence and repeatability of detection. Cornea 1999;18:34-46.

17. Barr JT, Zadnik K, Wilson BS, et al. Factors associated with corneal scarring in the Collaborative Longitudinal Evaluation of Keratoconus (CLEK) Study. Cornea 2000;19:501-507.

18. Barr JT, Wilson BS, Gordon MO, et al. Estimation of the incidence and factors predictive of corneal scarring in the Collaborative Longitudinal Evaluation of Keratoconus (CLEK) Study. Cornea 2006;25:16-25. 
19. Zadnik K, Barr JT, Gordon MO, Edrington TB. Biomicroscopic signs and disease severity in keratoconus. Collaborative Longitudinal Evaluation of Keratoconus (CLEK) Study Group. Cornea 1996;15:139146.

20. Zadnik K, Steger-May K, Fink BA, et al. Between-eye asymmetry in keratoconus. Cornea 2002;21:671-679.

21. Nichols JJ, Steger-May K, Edrington TB, Zadnik K. The relation between disease asymmetry and severity in keratoconus. Br J Ophthalmo 2004;88:788-791.

22. Shen JF, McMahon TT, Cheng EL, et al. Lysosomal hydrolase staining of conjunctival impression cytology specimens in keratoconus. Cornea 2002;21:447-452.

23. Maeda N, Fujikado T, Kuroda T, et al. Wavefront aberrations measured with Hartmann-Shack sensor in patients with keratoconus. Ophthalmology 2002;109:1996-2003.

24. Liu E, Slomovic AR. Indications for Penetrating Keratoplasty in Canada, 1986-1995. Cornea 1997;16:414-419.

25. Amaral Cde S, Duarte JY, Silva PL, et al. Indications for penetrating keratoplasty in Pernambuco. Arq Bras Oftalmol 2005;68:635-637.

26. Zhang $\mathrm{C}, \mathrm{Xu}$ J. Indications for penetrating keratoplasty in East China, 1994-2003. Graefe's Archive for Clinical and Experimental Ophthalmology 2005;243:1005-1009.

27. Kang PC, Klintworth GK, Kim T, et al. Trends in the Indications for Penetrating Keratoplasty, 1980-2001. Cornea 2005;24:801-803.

28. Weed $\mathrm{KH}, \mathrm{McGhee} \mathrm{CN}$. Referral patterns, treatment management and visual outcome in keratoconus. Eye 1998;12:663-668.

29. Tuft SJ, Moodaley LC, Gregory WM, Davison CR, Buckley RJ. Prognostic factors for the progression of keratoconus. Ophthalmology 1994;101:439-447.

30. Reeves SW, Stinnett S, Adelman RA, Afshari NA. Risk Factors for Progression to Penetrating Keratoplasty in Patients With Keratoconus. American Journal of Ophthalmology 2005;140:607-611.

31. Caporossi A, Balestrazzi A, Simi C, et al. Manual Deep Lamellar Keratoplasty: Alternative Methods and Air-Guided Technique. Transplantation Proceedings 2005;37:2697-2701.

32. Bilgihan K, Ozdek SC, Sari A, Hasanreisoglu B. Microkeratome-assisted lamellar keratoplasty for keratoconus: stromal sandwich. Journal of Cataract \& Refractive Surgery 2003;29:1267-1272.

33. Busin M, Zambianchi L, Arffa RC. Microkeratome-Assisted Lamellar Keratoplasty for the Surgical Treatment of Keratoconus. Ophthalmology 2005;112:987-997

34. Dupuy FP, Salvoldelli M, Robert AM,et al. Chemotactic penetration of keratocytes in ePTFE polymer in vitro. J Biomed Mater Res 2001;56:487493.

35. Bleckmann H, Holak S. Preliminary results after implantation of four AlphaCor artificial corneas. Graefe's Archive for Clinical and Experimental Ophthalmology 2006;244:502-506.

36. Alio JL, Artola A, Ruiz-Moreno JM, et al. Changes in keratoconic corneas after intracorneal ring segment explantation and reimplantation. Ophthalmology 2004;111:747-751.

37. Alio JL, Artola A, Hassanein A, et al. One or 2 Intacs segments for the correction of keratoconus. Journal of Cataract \& Refractive Surgery 2005;31:943-953.

38. Hellstedt T, Makela J,Uusitalo R, et al. Treating Keratoconus With Intacs Corneal Ring Segments. Journal of Refractive Surgery 2005;21:236-246.

39. Hladun L, Harris M. Contact lens fitting over intrastromal corneal rings in a keratoconic patient. Optometry 2004;75:48-54.

40. Boxer Wachler BS, Christie JP, Chandra NS, et al. Intacs for keratoconus. Ophthalmology 2003;110:1031-1040.

41. Colin J, Cochener B, Savary G,et al. INTACS inserts for treating keratoconus: One-year results. Ophthalmology 2001;108:1409-1414.

42. Kwitko S, Severo NS. Ferrara intracorneal ring segments for keratoconus. Journal of Cataract \& Refractive Surgery 2004;30:812-820.

43. Levinger S, Pokroy R. Keratoconus Managed With Intacs: One-Year Results. 2005:123:1308-1314.

44. Siganos D, Ferrara P, Chatzinikolas K, et al. Ferrara intrastromal corneal rings for the correction of keratoconus. Journal of Cataract \& Refractive
Surgery 2002;28:1947-1951.

45. Tunc Z, Devici N, Sener B, Bahcecioglu H. [Corneal ring segments (INTACS) for the treatment of asymmetrical astigmatism of the keratoconus. Follow-up after 2 years]. J Fr Ophtalmol 2003;26:824-830.

46. Mularoni A, Torreggiani A, di Biase A, et al. Conservative Treatment of Early and Moderate Pellucid Marginal Degeneration: A new refractive approach with intracorneal rings. Ophthalmology 2005;112:660-666.

47. Miranda D, Sartori M, Francesconi C, et al. Ferrara intrastromal corneal ring segments for severe keratoconus. J Refract Surg 2003;19:645-653.

48. Kasparova EA. [Pathogenetic basis for treatment of primary keratoconus by a combined method of excimer laser surgery (combination of photorefraction and phototherapeutic keratectomy)]. Vestn Oftalmol 2002;118:21-25.

49. Kasparova EA, Kasparov AA. Six-year experience with excimer laser surgery for primary keratoconus in Russia. J Refract Surg 2003;19:S250254.

50. Tamayo Fernandez GE, Serrano MG. Early clinical experience using custom excimer laser ablations to treat irregular astigmatism. Journal of Cataract \& Refractive Surgery 2000;26:1442-1450.

51. Tamayo GE, Serrano MG. Treatment of irregular astigmatism and keratoconus with the VISX C-CAP method. Int Ophthalmol Clin 2003;43:103-110.

52. Colin J, Simonpoli S. [Keratoconus: current surgical options]. J Fr Ophtalmol 2005;28:205-217.

53. Rowsey JJ, Gills JP, Gills III P. Treating Keratoconus with Astigmatic Keratotomy and Intraocular Lenses: A New Approach. SO International Ophthalmology Clinics Summer 2003;43(3):81-92.

54. Colin J, Velou S. Implantation of intacs and a refractive intraocular lens to correct keratoconus. Journal of Cataract \& Refractive Surgery 2003;29:832-834.

55. Budo C, Bartels MC, van Rij G. Implantation of Artisan Toric Phakic Intraocular Lenses for the Correction of Astigmatism and Spherica Errors in Patients With Keratoconus. Journal of Refractive Surgery 2005;21:218-222.

56. Wollensak G, Spoerl E, Seiler T. Riboflavin/ultraviolet-a-induced collagen crosslinking for the treatment of keratoconus. American Journal of Ophthalmology 2003;135:620-627.

57. Wollensak G, Spoerl E, Wilsch M, Seiler T. Endothelial cell damage after riboflavin-ultraviolet-A treatment in the rabbit. Journal of Cataract \& Refractive Surgery 2003;29:1786-1790.

58. Wollensak G, Sporl E, Reber F,et al. Corneal endothelial cytotoxicity of riboflavin/UVA treatment in vitro. Ophthalmic Res 2003;35:324-328.

59. Wollensak G, Spoerl E, Wilsch M, Seiler T. Keratocyte Apoptosis After Corneal Collagen Cross-linking Using Riboflavin/UVA Treatment. Cornea 2004;23:43-49.

60. Kampmeier J, Behrens A, Wang Y, et al. Inhibition of Rabbit Keratocyte and Human Fetal Lens Epithelial Cell Proliferation by RetrovirusMediated Transfer of Antisense Cyclin G1 and Antisense MAT1 Constructs. Hum Gene Ther 2000:11:1-8.

61. Mohan RR, Schultz GS, Hong J-W, et al. Gene transfer into rabbit keratocytes using AAV and lipid-mediated plasmid DNA vectors with a lamellar flap for stromal access. Experimental Eye Research 2003;76:373383.

62. Oshima Y, Sakamoto T, Hisatomi T, et al. Targeted Gene Transfer to Corneal Stroma in vivo by Electric Pulses. Experimental Eye Research 2002;74:191-198.

63. Seitz B, Moreira L, Baktanian E, et al. Retroviral vector-mediated gene transfer into keratocytes in vitro and in vivo. American Journal of Ophthalmology 1998;126:630-639.

64. Wang D-A, Du H, Jaggar JH, et al. Injury-elicited differential transcriptional regulation of phospholipid growth factor receptors in the cornea. 2002:283:C1646-1654.

65. Dean DA, Byrd JN Jr, Dean BS. Nuclear targeting of plasmid DNA in human corneal cells. Current Eye Research 1999;19:66-75.

66. Yan X, Rong P. [Influence on human keratocyte proliferation by cationic liposome mediated transfer of p21WAF1]. Zhonghua Yan Ke Za Zhi 2002;38:103-107. 